\title{
Insights from animal models of myocardial infarction: do ACE inhibitors limit the structural response?
}

\author{
Jos F M Smits, Mat J A P Daemen
}

Inhibitors of angiotensin converting enzyme (ACE) are now used extensively to treat myocardial infarction. Large studies have shown beneficial effects on morbidity and mortality. ${ }^{1}$ The beneficial effect seems to be mediated, at least in part, by intervention in the complex changes in ventricular structure. This type of change is referred to as "ventricular remodelling." In spite of their successful application in myocardial infarction, several issues remain to be resolved. Theoretically, the mechanisms that mediate the response, such as the nature of the angiotensin receptors and their localisation in the heart or the periphery, need to be known to understand the effect. Such knowledge may also help to solve practical questions related to the treatment of patients with infarction, such as dosing and timing of treatment. With respect to the timing of treatment, several studies are currently under way to compare immediate and later treatment in patients with infarction. Animal experiments have provided not only a theoretical framework but also functional data suggesting that immediate treatment may evoke adverse effects.

\section{Cardiac remodelling after myocardial infarction}

REMODELLING OF THE INFARCT

An infarct results in cardiomyocyte oedema and necrosis. Myocyte necrosis is followed by a wound healing response, which comprises a local inflammatory reaction, excessive deposition of extracellular matrix, angiogenesis, and the appearance of myofibroblasts to increase the tensile strength of the infarct. ${ }^{2}$ Dilatation and thinning, also called infarct expansion, ${ }^{13}$ are the most important structural changes in the tissue in an infarct; they are, however, not only caused by myocyte necrosis but also by myocyte slippage. ${ }^{4}$ Infarct expansion is limited to the first weeks after myocardial infarction, can ultimately lead to a ventricular aneurysm, and is negatively correlated with ventricular function and prognosis.

REMODELLING OF THE NON-INFARCTED VENTRICLE

Ventricular dilatation

The non-infarcted ventricle also remodels to compensate for the loss of viable tissue and to maintain cardiac function. This remodelling entails ventricular dilatation, which is initially beneficial to maintain stroke volume. Ventricular dilatation, however, also increases ventricular wall stress, which may stimulate further ventricular enlargement. ${ }^{1}$

\section{Myocytes}

Ventricular remodelling also includes important changes in the quantity and quality of myocytes. The volume, orientation, and possibly number of myocytes change, ${ }^{6-9}$ but the changes in myocyte mass, which are initiated by the increased wall stress, do not fully compensate for the loss of viable tissue and for the loss of function. One of the possible explanations for this apparent paradox - that is, more cardiac mass without improved cardiac function-is that cardiac hypertrophy is associated with alterations in the quantity and quality of the expression of contractile, cytoskeletal, and neurohormonal genes. This results in re-expression of the fetal phenotype-that is, the re-expression of proteins that had been present in fetal life but had disappeared in adulthood. ${ }^{10}$ Although the most extensive studies in this respect have been performed in (small) animals, similar changes have been documented in humans. ${ }^{11}$ The presence of these fetal proteins is associated with decreased contractility and lower energy demand of the cardiac muscle. For instance, the expression of the gene of the heavy chain of the contractile protein myosin changes from the $\alpha$ to the $\beta$ chain, which contracts more slowly but is less energy consuming. ${ }^{12}$

\section{Endothelium}

Although there is a substantial growth in the number and length of capillaries in the noninfarcted myocardium, this increase is insufficient to meet the increase in cardiomyocyte hypertrophy and the decrease in the ratio of capillaries to cardiomyocytes during ventricular remodelling after myocardial infarction. ${ }^{13}$ The increase in distance between capillaries and the decrease in density of capillary profiles during ventricular remodelling leads to relative energy starvation. ${ }^{14}$ The expression of a less energy consuming phenotype (see above) may be seen as an adaptation to the energy starvation of hypertrophied cardiomyocytes but is detrimental to contractility. ${ }^{14}$ 


\section{Extracellular matrix}

The fibrillar collagens, type I and type III, are the major components of the cardiac extracellular matrix. The amount and distribution of these fibrillar collagens in the myocardium are important denominators of cardiac function, and changes in the amount and distribution of collagen can affect the function of the heart. For instance, an increased collagen fraction increases the stiffness of the heart, leading to decreased compliance and diminished diastolic filling. Increased intercellular and pericellular collagen fibres may limit myocyte motion and decrease the compliance of the ventricle. Also, arrhythmias may result from increased collagen deposition. Fibrillar collagens accumulate in the cardiac interstitium during aging ${ }^{15}$ but also during cardiac hypertrophy induced by pressure overload. ${ }^{16}$ The amount of collagen also increases during ventricular remodelling after myocardial infarction in rats and humans. ${ }^{18-20}$ The amount of fibronectin, which provides the scaffold for the deposition of collagen, also increases shortly after the induction of cardiac hypertrophy. ${ }^{21} 22$

Structural changes in the interstitium are associated with a change in DNA synthesis. In rats in which the left coronary artery had been ligated to induce a myocardial infarction DNA synthesis increased within the first two weeks in both the non-infarcted left and right ventricles. The increased DNA synthesis was found predominantly in fibroblasts and endothelial cells and only to a minor extent in cardiomyocytes. ${ }^{2023}$

\section{Role of the renin-angiotensin system in ventricular remodelling}

The mechanisms that govern the above described remodelling response of the heart after a myocardial infarction remain to be largely elucidated. Obviously, mechanical stress imposed on the remaining ventricle after an ischaemic insult may be important. The observation that the response is not limited to the left ventricle suggests, however, that other factors may be important. In this respect, the renin-angiotensin system has been extensively investigated; it is of interest because of the beneficial effects of ACE inhibitors in myocardial infarction, both in experimental animals and in humans.

The renin-angiotensin system is no longer considered to be an exclusively circulating hormone system. Evidence has accumulated that several tissues, including the heart, express all the components necessary to form renin and angiotensin locally. ${ }^{24}$ Expression of angiotensinogen, renin, and ACE has been shown in messenger RNA, as well as in proteins in cardiac myocytes and cardiac fibroblasts. Of special interest are the observations that expression of angiotensinogen messenger $\mathrm{RNA}^{25}$ and ACE messenger RNA ${ }^{26}$ is increased in the remaining myocardium after myocardial infarction in rats. In fact, the increased wall stress under these conditions correlated with angiotensinogen expression ${ }^{25}$ and ACE expression correlated with the extent of myocardial infarction, ${ }^{26}$ suggesting local regulation of the activity of the cardiac reninangiotensin system. What then are the pathophysiological implications with respect to remodelling after infarction?

In a recent review, Dzau discusses the possible functional role of tissue reninangiotensin systems. ${ }^{27}$ Angiotensin II may influence cardiac inotropy and chronotropy. ${ }^{27}$ The effect could be indirect - that is, through presynaptic activation of the sympathetic nervous system. Through the same indirect mechanism angiotensin II could have a trophic effect. $\alpha$ Adrenoceptor stimulation stimulates hypertrophy in neonatal rat cardiac myocytes. ${ }^{28}$ Alternatively, angiotensin II could have direct effects on cardiac cells. Angiotensin II has trophic effects on cardiac myocytes that are independent of its effect on blood pressure and mediated entirely through $\mathrm{AT}_{1}$ angiotensin receptors. ${ }^{29}$

A role for this mechanism in the cardiac hypertrophy following myocardial infarction in rats was suggested by the total inhibition of hypertrophy we observed after infusion of the $\mathrm{AT}_{1}$ antagonist losartan in infarcted rats. ${ }^{30}$ Although cardiomyocytes represent the bulk of the mass of the heart, and changes in cardiac weight may be interpreted as changes in cardiac myocyte mass, at least two major cell types represent the bulk of the cell number: cardiac fibroblasts and endothelial cells lining the coronary circulation. In contrast to cardiomyocytes, these cells are capable of replicating; this may have consequences for cardiac stiffness and perfusion, respectively. In cell culture cardiac fibroblasts show a mitogenic response to angiotensin II. ${ }^{31}$ Again, this response was mediated by $\mathrm{AT}_{1}$ receptors. ${ }^{31} \mathrm{We}$ found that losartan inhibits collagen synthesis in vivo after myocardial infarction in rats, ${ }^{30}$ suggesting a functional role for this effect. The response of endothelial cells after myocardial infarction may operate through a different mechanism. About $30 \%$ of cells proliferating in the myocardium after an infarction are endothelial cells. ${ }^{23}$ This suggests vascular outgrowth in the (hypertrophying) myocardium. Interestingly, losartan blocked only part of the proliferative response to infarction in rats. ${ }^{30}$ Since collagen synthesis was blocked completely, this suggests that the endothelial response may be spared by losartan, and, thus, be mediated by another pathway. In this respect it is noteworthy that in a model for vascular neogenesis - the chick chorioallantoic membrane-angiotensin II induces a potent neovascularisation response that is resistant to losartan and the non-peptidergic $\mathrm{AT}_{2}$ antagonist PD 123319 but may be completely inhibited by the peptidergic $\mathrm{AT}_{2}$ antagonist CGP42112A. ${ }^{32}$ This suggests that a non-AT receptor may be important in this part of the response.

\section{Remodelling during ACE inhibition}

Pfeffer et al were the first to show the effect of long term captopril treatment in rats after 
myocardial infarction, not only on cardiac function $^{33}$ but also on survival. ${ }^{34}$ Increased survival was also observed with enalapril treatment, ${ }^{35}$ indicating that this might be a general effect of ACE inhibitors. For captopril the functional improvement was associated with inhibition of cardiac hypertrophy and dilatation, whereas cardiac stiffness did not increase. ${ }^{33}$ The functional improvement was not the result of decreased afterload since it could not be mimicked by hydralazine in rats at a dose that reduced blood pressure to a similar extent. ${ }^{36}$ Similarly, zofenopril but not the $\alpha$ adrenoceptor blocking drug terazosin effectively inhibits the remodelling response in dogs in which myocardial infarction was induced by direct current transmyocardial shock. ${ }^{37}$ Francis et al suggested that the difference in response depends on differential effects on preload, based on measurements of venous capacitance. ${ }^{37}$ This concept has been corroborated in studies comparing the effects of enalapril and combined hydralazine-nitrate treatment in humans with heart failure ${ }^{38}$; both treatments improved survival, although enalapril was more effective than the combined vasodilator treatment. The alternative, based on the observed activation of the reninangiotensin system after infarction and the greater effectiveness of enalapril cited above, is a specific interaction with the circulating or local renin-angiotensin system. The effect of ACE inhibitors could also be due to the increased bradykinin concentrations as ACE inhibitors also prevent the degradation of bradykinin. ${ }^{39}$ This is supported by the results of a study in dogs in which the bradykinin antagonist HOE 140 blocked the effects of the ACE inhibitor ramipril on infarct size. ${ }^{40}$ Detailed studies on the effects of bradykinin on cardiac remodelling processes are, however, not available.

We have investigated the effects of captopril on cardiac structure and function after myocardial infarction in rats. The early increase in interstitial DNA synthesis and collagen deposition was completely inhibited by treatment with captopril given immediately after infarction. ${ }^{20}$ Hydralazine, at a dose that causes a comparable reduction in peripheral resistance, actually increased interstitial DNA synthesis further, ${ }^{20}$ again suggesting that afterload reduction is not an overriding factor. As discussed above, this response is, in part, mediated through $\mathrm{AT}_{1}$ receptors. ${ }^{30}$ These structural responses were associated with a complex effect on cardiac function, resulting in a decreased stroke volume and increased heart rate. ${ }^{41}$ This suggests that the early structural response is physiological rather than

Structural and functional effects of differential inhibition of renin-angiotensin system after myocardial infarction in rats ${ }^{20} 3041$

\begin{tabular}{lllll}
\hline & Effect on: & & & \\
\cline { 2 - 5 } & Heart weight & Collagen content & Total DNA synthesis & Cardiac function \\
\hline Losartan early & Decreased & Decreased & None & None \\
$\begin{array}{l}\text { Captopril: } \\
\text { Early }\end{array}$ & Decreased & Decreased & Decreased & Decreased \\
Late & Decreased & None & None & Increased \\
\hline
\end{tabular}

pathological. In contrast, once the early response had subsided-that is, three weeks after the infarction ${ }^{20}$ - treatment with the same dose of captopril did improve cardiac function. ${ }^{41}$ In our studies treatment lasted for two weeks-that is, from three to five weeks after infarction. This period may have been too brief for a clear regression of structural changes other than hypertrophy. Litwin et al treated rats with captopril from three to six weeks after infarction and also did not note an effect on collagen deposition or cardiac stiffness. ${ }^{42}$ In contrast, Michel et al found that two months of perindopril treatment was associated with diminution of collagen deposition and cardiac stiffening. ${ }^{18}$ This discrepancy may be related to the long half life of cross linked collagens. It is important to note that ACE inhibition does not inhibit all forms of collagen deposition, as we have never observed interference with scar formation in the infarcted area.

The most prominent results from our studies with captopril and losartan in rats are summarised in the table. They suggest that the effects on collagen deposition do not play an overriding part in the functional outcome. Inhibition of interstitial collagen deposition by early treatment with losartan or captopril had different effects on function ${ }^{20} 3041$ but similar effects on collagen content. This suggests that the early response to captopril is associated with inhibition of total cell proliferation-that is, fibroblasts and endothelial cells - and may be related to inhibition of formation of collaterals in the hypertrophying heart.

\section{Conclusions}

Our knowledge of the processes that occur in the heart after myocardial infarction is rapidly expanding. In parallel, the treatment of patients suffering from infarction has greatly improved, primarily by the introduction of ACE inhibitors to treatment. However, because of the lack of understanding of the mechanistic relation between these two-that is, not if, but how ACE inhibitors interfere with the remodelling process-basic questions remain unanswered. These pertain to problems about whether the circulating or the local reninangiotensin system is the primary therapeutic target, and, consequently, which (if any) ACE inhibitor may be optimal at what dosing regimen. With respect to dosing regimen, our data from animal experiments suggesting delayed, rather than immediate treatment, have been confirmed in trials in patients. ${ }^{43}$ Basic as well as clinical research will have to address these primary questions in order to rationalise treatment in patients with myocardial infarction.

1 Pfeffer MA Braunwald E Ventricular remodeling after myocardial infarction. Experimental observations after myocardial infarction. Experimental observations and clinical $1161-72$

2 Vracko R, Thorning D. Contractile cells in rat myocardial scar tissue. Lab Invest 1991;65:221-7.

3 Hutchins GM, Bulkey BH. Infarct expansion versus extension: two different complications of acute myocardial infarction. Am $\mathscr{f}$ Cardiol 1978;41: $1127-32$. 
4 Cooper G IV, Mercer WE, Hoober JK, et al. Load regulation of the properties of adult feline cardiocytes. The role of substrate adhesion. Circ Res 1986;58: 692-705.

5 Tsutsui H, Ishihara K, Cooper G IV. Cytoskeletal role in the contractile dysfunction of hypertrophied myocardium. Science 1993;260:682-7.

6 Anversa P, Beghi C, Kikkawa Y, Olivetti G. Myocardial response to infarction in the rat-morphometic measurement of infarct size and myocyte cellular hypertrophy. Am $\mathcal{f}$ Pathology 1985;118:484-92.

7 Olivetti G, Ricci R, Anversa P. Hyperplasia of myocyte nuclei in long-term cardiac hypertrophy in rats. 7 Clin Invest 1987;80:1818-21.

8 Anversa P, Fitzpatrick D, Argani S, Capasso JM. Myocyte mitotic division in the aging mammalian rat heart. Circ mitotic division in the

9 Capasso JM, Bruno S, Cheng W, et al. Ventricular loading is coupled with DNA synthesis in adult cardiac myocytes is coupled with DNA synthesis in adult cardiac myocytes Res 1992;71:1379-89.

10 Boheler KR, Schwartz K. Gene expression in cardiac hypertrophy. Trends in Cardiovascular Medicine 1992;2: 176-82.

11 Lompre AM, Mercadier JJ, Schwartz K. Changes in gene expression during cardiac growth. International fournal of Cytology 1991;124:137-86.

12 Schwartz K, Boheler KR, De La Bastie D, Lompre AM, Mercadier JJ. Switches in cardiac muscle gene expression as a result of pressure and volume overload. Am $\mathcal{J}$ Physiol 1992;262:R364-9.

13 Olivetti G, Anversa P. Long term pressure induced cardiac hypertrophy: capillary and mast cell production. $A m \mathcal{F}$ Physiol 1989;257:H1766-72.

14 Katz A. Cardiomyopathy of overload. $N$ Engl $\mathcal{f}$ Med 1990;322:100-10.

15 Chapman D, Weber KT, Eghbali M. Regulation of fibrillar collagen types I and II and basement type IV collagen gene expression in pressure overloaded rat myocardium. Circ Res 1990;67:787-94.

16 Weber KT, Brilla CG. Pathological hypertrophy and cardiac interstitium. Circulation 1991;83:1849-65.

17 Weber KT, Anversa P, Armstrong PW, et al. Remodeling and reparation of the cardiovascular system. $\mathcal{F} \mathrm{Am} \mathrm{Coll}$ Cardiol 1992;20:3-16.

18 Michel J, Lattion A, Salzmann J, et al. Hormonal and cardiac effects of converting enzyme inhibition in rat myocardial infarction. Circ Res 1988;62:641-50.

19 Volders PGA, Willems IEMG, Cleutjens JPM, Arends JW, Havenith MG, Daemen MJAP. Interstitial collagen is increased in the non-infarcted myocardium after myocardial infarction. $\mathcal{f}$ Mol Cell Cardiol 1993;25:317-23.

20 van Krimpen C, Smits JFM, Cleutjens JPM, et al. DNA synthesis in the non-infarcted cardiac interstitium is increased after left coronary artery ligation in the rat: effects of captopril. $\mathcal{F}$ Mol Cell Cardiol 1991;23: 1245-53.

21 Shekhonin BV, Guriev SB, Irgashev SB, Koteliansky VE. Immunofluorescence identification of fibronectin and fibrinogen/fibrin in experimental myocardial infarction. f Mol Cell Cardiol 1990;22:533-41.

22 Samuel J, Barrieux A, Dufour S, et al. Accumulation of fetal fibronectin mRNAs during the development of rat cardiac hypertrophy induced by pressure overload. $\mathcal{f}$ Clin cardiac hypertrophy ind

23 Kuizinga MC, Cleutjens JPM, Smits JFM, Daemen MJAP. Griffonia simplicifolia I (GSI): a suitable rat cardiac
microvascular marker on paraffin embedded tissue. $₹ \mathrm{Mol}$ microvascular marker on paraffin emb

24 Lee YA, Lindpaintner K. The cardiac renin-angiotensin system: from basic research to clinical relevance. Drug Research 1993:43:201-6.

25 Lindpaintner K, Lu W, Neidermajer N, et al. Selective activation of cardiac angiotensinogen gene expression in post-infarction ventricular remodeling in the rat. $\mathcal{f ~} \mathrm{Mo}$ Cell Cardiol 1993;25:133-43.
26 Hirsch AT, Talsness CE, Schunkert H, Paul M, Dzau VJ. Tissue-specific activation of cardiac angiotensin converting enzyme in experimental heart failure. Circ Res 1991;69:475-82.

27 Dzau VJ. Tissue renin-angiotensin system in myocardial hypertrophy and failure. Arch Intern Med 1993;153: 937-42.

28 Simpson P. Stimulation of hypertrophy of cultured neonatal rat heart cells through an alpha 1-adrenergic receptor and induction of beating through an alpha 1- and beta 1-adrenergic receptor interaction. Evidence for independent regulation of growth and beating. Circ Res 1985;56:884-94.

29 Dostal DE, Baker KM. Angiotensin II stimulation of left ventricular hypertrophy in adult rat heart. Mediation by the AT1 receptor. Am F Hypertens 1992;5:276-80.

30 Smits JF, van-Krimpen C, Schoemaker RG, Cleutjens JP, Daemen MJ. Angiotensin II receptor blockade after myocardial infarction in rats: effects on hemodynamics, myocardial DNA synthesis, and interstitial collagen content. f Cardiovasc Pharmacol 1992;20:772-8.

31 Schorb W, Booz GW, Dostal DE, Conrad KM, Chang KC Baker KM. Angiotensin II is mitogenic in neonatal rat cardiac fibroblasts. Circ Res 1993;72:1245-54.

32 Le-Noble FA, Schreurs NH, van-Straaten HW, et al. Evidence for a novel angiotensin II receptor involved in angiogenesis in chick embryo chorioallantoic membrane. Am F Physiol 1993;264:R460-5.

33 Pfeffer JM, Pfeffer MA, Braunwald E. Influence of chronic captopril therapy on the infarcted left ventricle of the rat. Circ Res 1985;57:84-95.

34 Pfeffer MA, Pfeffer JM, Steinberg C, Finn P. Survival after an experimental myocardial infarction: beneficial effects of long-term therapy with captopril. Circulation 1985;72 406-12.

35 Sweet CS, Emmert SE, Stabilito II, Ribeiro LG. Increased survival in rats with congestive heart failure treated with enalapril. $f$ Cardiovasc Pharmacol 1987;10 636-42.

36 Raya T, Gay R, Aguirre M, Goldman S. Importance of venodilatation in prevention of left ventricular dilatation after chronic large myocardial infarction in rats: a comparison of captopril and hydralazine. Circ Res 1989; 64:330-7.

37 Francis GS, McDonald KM, Cohn IN. Neurohumoral activation in preclinical heart failure. Remodeling and the potential for intervention. Circulation 1993;87(suppl):

38 Cohn JN, Archibald DG, Ziesche S, et al. Effect of vasodilator therapy on mortality in chronic congestive heart failure. Results of a Veterans Administration Cooperative Study. N Engl F Med 1986;314:1547-52.

39 Martorana PA, Scholkens BA. Does bradykinin play a role in the cardiac antiischemic effect of the ACE-inhibitors? Basic Res Cardiol 1991;86:293-6.

40 Martorana P, Kettenbach B, Breipohl G, Linz W, Scholkens B. Reduction of infarct size by local angiotensin converting enzyme inhibition is abolished by a bradykinin antagonist. Eur $\mathcal{f}$ Pharmacol 1990;182: 395-6.

41 Schoemaker RG, Debets JJM, Struyker-Boudier HAJ, Smits JFM. Delayed but not immediate captopril therapy improves cardiac function in conscious rats, following myocardial infarction. $\mathcal{f} \mathrm{Mol}$ Cell Cardiol 1991;23: 187-97.

42 Litwin SE, Litwin CM, Raya TE, Warner AL, Goldman S. Contractility and stiffness of noninfarcted myocardium after coronary ligation in rats. Effects of chronic angiotensin con

43 Swedberg K, Held P, Kjekdhus J, et al. Effects of the early administration of enalapril on mortality in patients with acute myocardial ifnarction-results of the cooperative new Scandinavian enalapril survival study (CONSENSUS II). N Engl $\mathfrak{f}$ Med 1992;327: 678-84. 